\title{
Carbon/sulfur composite cathodes for flexible lithium/sulfur batteries: status and prospects
}

\author{
Yan Zhao 1,2, Yongguang Zhang 1,2, Zagipa Bakenova ${ }^{3,4}$ and Zhumabay Bakenov ${ }^{3,4}$ * \\ ${ }^{1}$ Research Institute for Energy Equipment Materials, Hebei University of Technology, Tianjin, China \\ ${ }^{2}$ Tianjin Key Laboratory of Laminating Fabrication and Interface Control Technology for Advanced Materials, Tianjin, China \\ ${ }^{3}$ Institute of Batteries LLC, Astana, Kazakhstan \\ ${ }^{4}$ Nazarbayev University, Astana, Kazakhstan
}

Edited by:

Xueliang Andy Sun, Western

University, Canada

Reviewed by:

Huan Pang, Anyang Normal

University, China; Nanjing University,

China

Jijeesh Ravi Nair, Politecnico Di Torino, Italy

Paulina Pólrolniczak, Institute of Non-Ferrous Metals Division in

Poznan Central Laboratory of

Batteries and Cells, Poland

*Correspondence:

Zhumabay Bakenov, Institute of

Batteries LLC, Kabanbay Batyr

Avenue 53, Astana 010000,

Kazakhstan

e-mail: zbakenov@nu.edu.kz
High specific energy and low cost flexible lithium/sulfur batteries have attracted significant attention as a promising power source to enable future flexible and wearable electronic devices. Here, we review recent progress in the development of free-standing sulfur composite cathodes, with special emphasis on electrode material selectivity and battery structural design. The mini-review is organized based on the dimensionality of different scaffold materials, namely one-dimensional carbon nanotube (CNT), two-dimensional graphene, and three-dimensional CNT/graphene composite, respectively. Finally, the opportunities and perspectives of the future research directions are discussed.

\footnotetext{
Keywords: lithium/sulfur battery, free-standing cathode, flexible batteries, high-performance batteries, high sulfur loading
}

\section{INTRODUCTION}

Facing the limited global energy supply and environmental issues, it is desirable to urgently explore the energy storage systems with high energy and power density (Zhang et al., 2011). Lithium rechargeable batteries are the most promising energy storage devices; however, the current cathode materials, such as those based on transition metal oxides and phosphates, have the maximum practically usable capacity limit of $200 \mathrm{mAh} \mathrm{g}^{-1}$ (Song et al., 2013a; Zhao et al., 2013). On the other hand, the high capacity anode materials such as transition metal oxides and the IV group materials (Yu et al., 2013) have been developed in the recent years. Therefore, the overall energy density of lithium rechargeable batteries is limited by the insufficient capacity of the available cathode materials.

Sulfur is a very attractive candidate as a cathode material due to its high theoretical specific capacity of $1672 \mathrm{mAh} \mathrm{g}^{-1}$, assuming complete reaction between $\mathrm{Li}$ and $\mathrm{S}\left(\mathrm{S}+2 \mathrm{Li}^{+}+2 \mathrm{e}^{-} \leftrightarrow \mathrm{Li}_{2} \mathrm{~S}\right)$ (Yang et al., 2013; Zhang et al., 2013d).

During an ideal discharge process, illustrated in Figure 1A, two main plateaus appear in the potential profiles, which are attributed to two main electrochemical reactions taking place at sulfur cathode upon cycling in Li/S battery (Yang et al., 2013). The first reaction, represented by a short discharge plateau at about $2.4 \mathrm{~V}$, is related to the formation of higher-order lithium polysulfides $\left(\mathrm{Li}_{2} \mathrm{~S}_{\mathrm{n}}, n \geq 4\right)$, which are soluble in most of liquid electrolytes. The following prolonged plateau around $2.0 \mathrm{~V}$ in the discharge profiles reflects the following electrochemical transition of the polysulfides into lithium sulfide $\mathrm{Li}_{2} \mathrm{~S}$, and the system's discharge capacity mainly depends on the $2 \mathrm{~V}$ plateau.

Other advantages of sulfur include its abundant resources, low cost, and environmental friendliness. Consequently, it is anticipated that $\mathrm{Li} / \mathrm{S}$ batteries will play an important role in the next generation energy storage systems (Zhao et al., 2012). However, wide-scale commercial use is so far limited because of several challenges that must be addressed.

Among these major problems restricting the use of this cathode, the insulating nature of sulfur (conductivity $\sim 5 \times 10^{-30} \mathrm{~S} \mathrm{~cm}^{-1}$, $25^{\circ} \mathrm{C}$ ) remains as one of the most challenging, leading to its low electrochemical utilization and limited rate capability, which necessitates the use of various conductive additives providing intimate contact between cathode particles (Bresser et al., 2013).

Another problem relates to the electrochemical processes upon Li/S battery operation: when elemental sulfur reacts with lithium ions to form $\mathrm{Li}_{2} \mathrm{~S}$, the lithium polysulfides are formed, which are easily dissolved in the majority of organic electrolytes. These intermediates can take part in the "sulfur shuttle mechanism" whereby the dissolved polysulfides can migrate onto the Li anode and form on its surface an electrochemically inactive layer consisting mainly of $\mathrm{Li}_{2} \mathrm{~S}_{2}$ and $\mathrm{Li}_{2} \mathrm{~S}$. These issues result in a low utilization of the active material, poor cycle life, and low system efficiency and negatively affect the anode operation as well (Evers and Nazar, 2013; Zhang et al., 2013a).

The third problem is related to the volume variation of sulfur particles during the charge and discharge operations. In this case, 


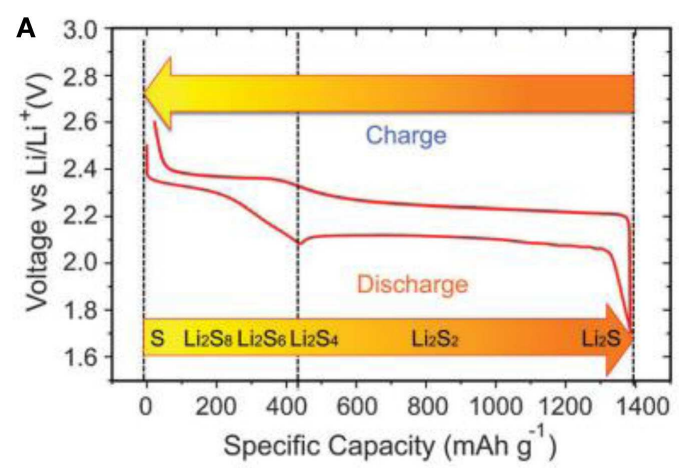

c
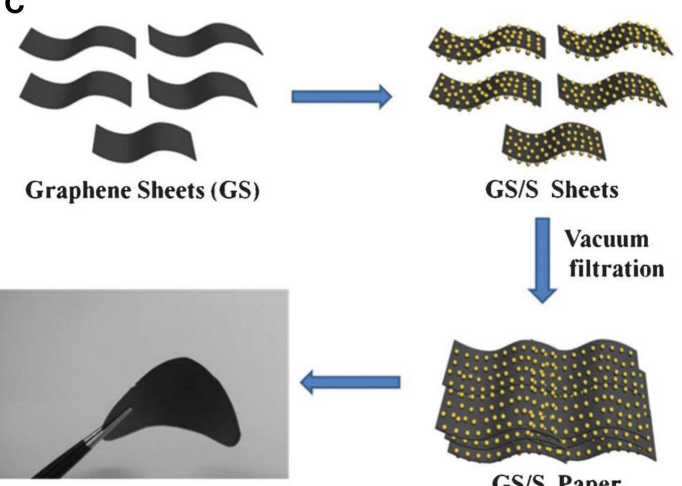

GS/S Paper

FIGURE 1 | (A) The voltage profile and chemistry of sulfur cathode in organic electrolytes. Reprinted with permission from Yang et al. (2013). Copyright (2013) Royal Society of Chemistry. (B) Schematics of the fabrication process of a self-weaving sulfur/MWCNT composite cathode synthesized by an in situ sulfur deposition method. Three simple steps to synthesize binder/current collector-free sulfur/MWCNT composite cathodes: (i) dispersion of MWCNTs, (ii) sulfur nucleation (yellow) onto MWCNTs, and (iii) vacuum filtration,

due to the different densities of sulfur $\left(2.07 \mathrm{~g} \mathrm{~cm}^{-3}\right)$ and final discharge product $\mathrm{Li}_{2} \mathrm{~S}\left(1.66 \mathrm{~g} \mathrm{~cm}^{-3}\right)$, sulfur experiences a noticeable volume expansion as large as $80 \%$, causing pulverization of active material and thus fast capacity fading (Wang et al., 2013).

Extensive efforts have been dedicated to improve the Li/S system, and various types of conductive carbon materials (Guo et al., 2011; Wang et al., 2012a; Zhao et al., 2013; Zhang et al., 2014b,c) and conductive polymers (Wang et al., 2002, 2012b,c; Zhang et al., 2012, 2013b,c,d,e,f, 2014a,d) have been used in order to enhance the electronic conductivity of the cathode composites, limit the dissolution of polysulfides into the electrolytes and buffer the volume changes of sulfur during the charge/discharge. To date, many interesting approaches have been successfully explored to develop sulfur cathodes with high-specific capacity and good cycle performance. For example, in Song et al.'s work (Song et al., 2013b), a novel CTAB-modified sulfur-graphene oxide nanocomposite has been developed, demonstrating a high initial discharge capacity of $1440 \mathrm{mAh} \mathrm{g}^{-1}$ at $0.2 \mathrm{C}$ and an excellent cycling performance up to 1500 cycles with a low capacity decay rate of $0.039 \%$ per cycle.

B

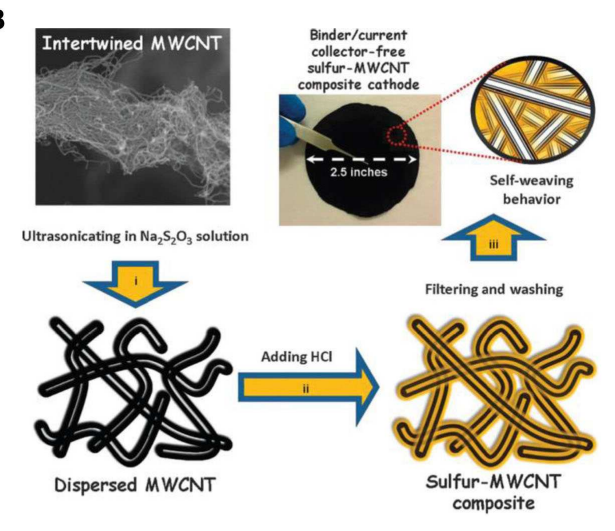

D

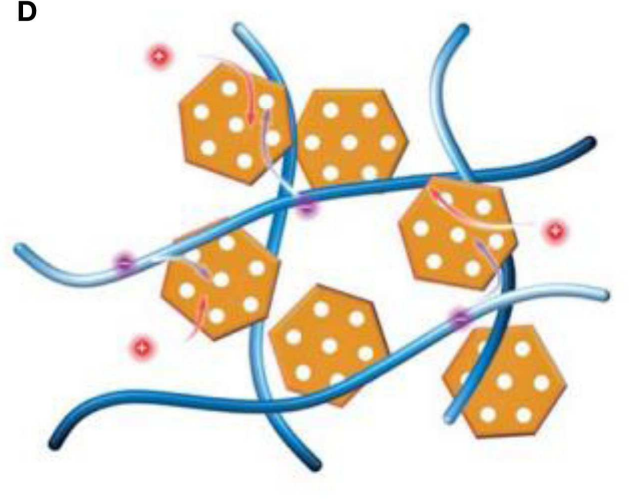

washing, and then drying. Reprinted with permission from Su et al. (2012). Copyright (2012) Royal Society of Chemistry. (C) Schematic illustration and photograph of the flexible self-supporting GS/S paper. Reprinted with permission from Jin et al. (2013a). Copyright (2012) Royal Society of Chemistry. (D) Schematics of sulfur cathode with CNT/carbon nanocage as scaffold. Reprinted with permission from Huang et al. (2014). Copyright (2014) Royal Society of Chemistry.
However, the enhancements in the electrochemical performance of sulfur cathode materials usually are compromised by the sulfur content in the sulfur composites or sulfur loading mass on the electrodes, which greatly reduces the overall energy density of lithium/sulfur cells. The increase of sulfur content usually leads to a very low conductivity of the sulfur composite; meanwhile, the optimal loading of sulfur in the porous structural composite is a balance between the desire for achieving the higher capacity and the allowance for the volume change to ensure the cathode stability (Wang et al., 2013).

Therefore, in the authors' view, the novel technologies beyond the traditional sulfur composite electrode could provide the possibility to maintain both good electrochemical performance and high sulfur content, which will provide high capacity and stable energy storage means. Among all possible technologies, the synthesis of free-standing sulfur cathode may be a promising promoter in improving the sulfur content in the electrodes in the same time maintaining the good electrochemical performance. In the common preparation routes for sulfur electrodes, a slurrycasting method is adopted and binders, such as PVDF and PTFE, 
are required at the ratio of $10 \mathrm{wt} \%$ or above in the whole electrode loading mass to ensure strong mechanical connections between active material, conductive additive, and current collector ( $\mathrm{Hu}$ and Sun, 2014; Zhou et al., 2014a). Thus, in the free-standing electrodes, elimination of the binder enables high sulfur fractions in the electrode of 0.90 or even higher, which leads to the higher sulfur content in electrode and the larger energy density. On the other hand, the area density of $\mathrm{Al}$ foils is about $5.0 \mathrm{mg} \mathrm{cm}^{-2}$, accounting for half of the total weight of the electrode. Hence, when metal current collector is replaced by a lightweight, flexible counterpart, the energy density of the battery can be remarkably improved (Gwon et al., 2014; Zhou et al., 2014a). Moreover, the exclusion of the common slurry-casting method simplifies the electrode preparation process, which could reduce the battery cost. The other obvious advantage of free-standing sulfur electrodes is an opportunity to facilitate their portability, meeting with the trends and requirements in the rechargeable lithium battery development, namely, light, thin, flexible, and small units (Lee et al., 2013; Zhou et al., 2014a).

In the process of development of free-standing electrodes, carbon-based active materials are mainly applied as the scaffold materials, due to their electrochemical activity and mechanical flexibility. Moreover, carbon nanotubes (CNTs), carbon nanofibers, and graphene exhibit a self-weaving behavior when being fabricated as a flexible film (Song et al., 2014; Zhou et al., 2014a).

Herein, we review recent progress in the development of freestanding sulfur composite cathodes, and this mini-review is organized based on the dimensionality of the different scaffold materials, namely one-dimensional CNT, two-dimensional graphene, and three-dimensional CNT/graphene composite, respectively. The synthesis of routes and electrochemical performance of flexible free-standing sulfur cathodes are briefly discussed as well. Finally, the opportunities and perspectives of future research directions are discussed.

\section{ONE-DIMENSIONAL CARBON NANOTUBE BASED SULFUR CATHODE}

Carbon nanotubes have been widely used in lithium-ion batteries due to their specific dimensional structure, good electronic conductivity, large activated surface area, and high flexibility. In the Li/S battery research, CNTs have been highly recommended as conductive additives to composite with sulfur, creating an electronically conductive network and reinforcing the structural stability (Yin et al., 2011). Moreover, CNT exhibit a self-weaving behavior when being fabricated as a flexible film ( $\mathrm{Su}$ et al., 2012).

Su et al. (2012) presented a self-weaving sulfur/multiwall CNT (S/MWCNT) composite synthesis by an in situ sulfur deposition method as shown in Figure 1B. The conductive MWCNTs act as a structural skeleton and support the integrity of the electrode. Furthermore, the interwoven structure of the composites could absorb $26 \mu \mathrm{L} \mathrm{cm}^{-2}$ of electrolyte, preserving the electrolyte and active materials within the MWCNT matrix. The highly conductive MWCNTs improve the active material utilization and cycle performance, due to the absorption ability of the cathode framework. The resulting S/MWCNT composite exhibits a high initial capacity of $1352 \mathrm{mAh} \mathrm{g}^{-1}$, and maintains a reversible capacity of $915 \mathrm{mAh} \mathrm{g}^{-1}$ at $1 \mathrm{C}$. Up to $3 \mathrm{C}$, the discharge capacity of $648 \mathrm{mAh} \mathrm{g}^{-1}$ still could be achieved. However, the large amounts of CNTs used in this composite to guarantee good electrochemical performance of the composite have resulted in a relatively low sulfur content of $40 \mathrm{wt} \%$.

The energy density is expected to be further increased if the content of CNTs is reduced. Jin et al. (2013b) reported that the sulfur/CNT composite film with the area density of $<5 \mathrm{mg} \mathrm{cm}^{-2}$ had a high sulfur content of $65 \mathrm{wt} \%$. This flexible composite film was prepared by coating an ultra-thin sulfur nanolayer on a preoxided CNT film through a simple two-step heating process. The porous and film-like CNT matrices enormously improve the electrical conductivity of sulfur and offer 3D pathways for fast $\mathrm{Li}$ ion diffusion. Moreover, based on the X-ray photoelectron spectra (XPS) studies, the formation of covalent bonds between sulfur and CNTs were confirmed, which guaranteed the structural stability of the composite film during the charge/discharge process. Consequently, the film electrode delivered an initial capacity of $1100 \mathrm{mAh} \mathrm{g}^{-1}$ and retained a reversible capacity of $740 \mathrm{mAh} \mathrm{g}^{-1}$ after 100 charge/discharge cycles at $0.1 \mathrm{C}$. It also exhibited a good rate capability and a reversible capacity of $520 \mathrm{mAh} \mathrm{g}^{-1}$ could be reached at the rate of $2 \mathrm{C}$.

Hagen et al. $(2012,2013)$ reported on a direct synthesis of a novel vertical-aligned CNT/sulfur (VACNT/S) composite electrode on the current collector without using any binder. The binder-free CNT cathodes were able to contain the highest total amount of the electrochemically active sulfur (90 wt\%) in the electrode among all published systems so far in the literature. The electrode was synthesized by employing a catalyst layer and a chemical vapor deposition (CVD) process. The CNTs were directly synthesized on the Ni current collector and sulfur was infiltrated using different approaches such as sublimation of sulfur, liquefied sulfur, melting of solid sulfur powder, and sulfurization through solvent. The sulfur mass in the resulting cathode could be varied between 3 and $20 \mathrm{mg} \mathrm{cm}^{-2}$ electrode leading to sulfur loads that are several times higher than that achieved in the slurry preparation method. The delivered capacities for these extremely high sulfur loads were reported to be around $900 \mathrm{mAh} \mathrm{g}^{-1}$ (sulfur) at a current density of $0.64 \mathrm{~mA} \mathrm{~cm}^{-2}$.

\section{TWO-DIMENSIONAL GRAPHENE-BASED SULFUR CATHODE}

Graphene is currently a viable carbon matrix material for Li/S battery applications due to its excellent properties, such as excellent electronic mobility, high specific surface area, high thermal conductivity, high mechanical strength, etc. (Bi et al., 2013).

Jin et al. (2013a) reported that a flexible self-supporting graphene-sulfur paper electrode was fabricated by a simple process with an in situ redox reaction followed by vacuum infiltration as illustrated in Figure 1C. This electrode showed a reversible discharge capacity of $600 \mathrm{mAh} \mathrm{g}^{-1}$ with $83 \%$ capacity retention after 100 cycles. The graphene framework served as both a conductive network and a supporting carrier for sulfur nanoparticles. A high capacity retention rate of $83 \%$ and an energy density of $804 \mathrm{Wh} \mathrm{kg}^{-1}$ were obtained for GS/S paper after 100 cycles. Furthermore, the thermal analysis results show that the sulfur content in the GS/S paper electrode was as high as $67 \mathrm{wt} \%$. 
The assembly of graphene sheets into porous structures can combine the excellent properties of graphene and the advantages of porous architectures. It was reported (Huang et al., 2013) that mesoporous graphene paper (MGP) was employed to immobilize elemental sulfur to obtain free-standing electrodes for high-performance $\mathrm{Li} / \mathrm{S}$ batteries. Amorphous sulfur was homogeneously distributed in the mesoporous architectures of porous graphene paper, in which sulfur was immobilized. The conductive flexible porous graphene networks could effectively facilitate electron transfer and support enhanced electrolyte diffusion. The free-standing sulfur/graphene nanocomposite electrodes achieved a high discharge capacity of $1393 \mathrm{mAh} \mathrm{g}^{-1}$ with an enhanced cycling stability and good rate performance.

A free-standing few-layered graphene (FLG) monolithic network foam was formed as a negative of a Ni metallic foam template by CVD followed by etching away of $\mathrm{Ni}$, and the sulfur/FLG foam composite cathode was prepared by infiltrating the sulfur solution into the FLG foam by drop casting (Xi et al., 2014). The FLG foam offers excellent electrical conductivity, an appropriate hierarchical pore structure to store the electro-active sulfur and facilitates the rapid electron/ion transport. The as-prepared electrode composite demonstrated excellent high-rate discharge stability as cathode in a Li/S cell. Compared with the fifth cycle discharge capacity, the capacity decay was as small as $0.064 \%$ per cycle at a high current density of $3200 \mathrm{~mA} \mathrm{~g}^{-1}$ and an average coulombic efficiency was about $96.2 \%$ over 400 cycles.

In order to improve the dispersibility of graphene in aqueous solution for preparation of cathode materials and prepare graphene oxide with high surface area, chemical stability, mechanical strength, and flexibility, the oxygen bonds were introduced into the carbon lattice in the forms of $-\mathrm{OH}, \mathrm{C}-\mathrm{O}-\mathrm{C}$, and $\mathrm{C}=\mathrm{O}$. Zhou et al. (2014b) reported that phenyl sulfonated functional groups $\left(\mathrm{PhSO}_{3}{ }^{-}\right)$were anchored on the graphene surface to increase the conductivity and water solubility of the carbon matrix. With these surface modifications, graphene was not only very easily dispersed in water but also existed as individual carbon sheets exhibiting excellent electrical conductivity, comparable to that of graphite, due to the restoration of an extensive conjugated $\mathrm{sp}^{2}$-carbon network. Phenyl sulfonated graphene sheets/sulfur $\left(\mathrm{PhSO}_{3}-\mathrm{RG} / \mathrm{S}\right)$ composite was obtained via an in situ redox reaction in aqueous solution and applied as the cathode material for lithium/sulfur battery. The additive-free $\mathrm{PhSO}_{3}-\mathrm{RG} / \mathrm{S}$ electrodes had a high initial discharge capacity of $900 \mathrm{mAh} \mathrm{g}^{-1}$, a good cycling life (460 $\mathrm{mAh} \mathrm{g}^{-1}$ after 400 cycles) at a current density of $0.2 \mathrm{C}$, and an excellent rate capability.

\section{THREE-DIMENSIONAL CARBON NANOTUBE/GRAPHENE-BASED SULFUR CATHODE}

Recently, a 3D conductive network was built by the incorporation of CNTs and mesoporous graphene-based materials by Huang et al. (2014) as schematically presented in Figure 1D. These two components as the building blocks were integrated through carbon deposition via high-temperature CVD, which ensured the high electrical conductivity throughout the electrode as well as the extraordinary mechanical stability. The graphene-based carbon nanocages derived from $\mathrm{MgO}$ templates demonstrated a high intrinsic electrical conductivity and sufficient meso-scale
Table 1 | Comparison of electrochemical performance of different sulfur composite.

\begin{tabular}{lcccc}
\hline Composite & \multicolumn{2}{c}{ Specific capacity $\left(\mathbf{m A h ~ g}^{-\mathbf{1}}\right)$} & C rate & $\begin{array}{c}\text { Sulfur } \\
\text { content (\%) }\end{array}$ \\
\hline S-MWCNT [1] & $1352\left(1^{\text {st }}\right)$ & $915\left(100^{\text {th }}\right)$ & 1 & 40 \\
S-CNT [2] & $1100\left(1^{\text {st }}\right)$ & $740\left(100^{\text {th }}\right)$ & 0.1 & 65 \\
GS/S [3] & $722\left(1^{\text {st }}\right)$ & $600\left(100^{\text {th }}\right)$ & 0.1 & 67 \\
MGP-S [4] & $1393\left(1^{\text {st }}\right)$ & $689\left(50^{\text {th }}\right)$ & 0.1 & 55 \\
S-FLG foam [5] & $1008\left(1^{\text {st }}\right)$ & $360\left(200^{\text {th }}\right)$ & 2 & 63 \\
S/CNT/carbon & $950\left(5^{\text {th }}\right)$ & $892\left(50^{\text {th }}\right)$ & 1 & 60 \\
nanocage [6] & & & & \\
CNT-S [7] & $1100\left(1^{\text {st }}\right)$ & $1000\left(40^{\text {th }}\right)$ & 0.076 & 60 \\
\hline
\end{tabular}

[1] Su et al. (2012); [2] Jin et al. (2013b); [3] Jin et al. (2013a); [4] Huang et al. (2013); [5] Xi et al. (2014); [6] Huang et al. (2014); [7] Hagen et al. (2012).

space to accommodate sulfur, which is expected to restrain the polysulfide shuttle. Electrochemical evaluation indicated that the rationally designed structure endowed the sulfur cathode with a high-specific capacity and rate performance. The initial discharge capacity of the electrode reached $1354 \mathrm{mAhg}^{-1}$ at $0.34 \mathrm{Ag}^{-1}$. Even at a current density of $8.35 \mathrm{Ag}^{-1}$, a reversible capacity of $750 \mathrm{mAh} \mathrm{g}^{-1}$ could still be preserved, which is about $70 \%$ of that at $0.84 \mathrm{Ag}^{-1}$.

\section{SUMMARY AND PROSPECTS}

Recently, lithium/sulfur (Li/S) batteries have received tremendous attention as high energy density storage devices because sulfur is a very attractive cathode material due to its low cost, high theoretical capacity and theoretical specific energy, abundance of the resources, and environmental friendliness. This mini-review presents the state of the art of the flexible Li/S battery research and technologies, and Table 1 summarizes some properties of some typical flexible Li/S batteries. Although research and development of free-standing lithium/sulfur batteries is still nascent, it can be seen from the Table 1 data that significant progress has been made in new sulfur cathode material development and in the processes for cathode preparation.

Mainly, CNT and graphene have been incorporated into the flexible electrodes as scaffold materials, greatly improving the electrodes performance. In spite of the achievements discussed in this review, there exists substantial room for the development of high-performance flexible Li/S batteries:

(1) The majority of the existing studies are based on half-cell flexible Li/S batteries. Both good performance flexible cathode and anode materials should be considered together for developing practical flexible full batteries (Zhou et al., 2014a). Beside this, in traditional batteries, a liquid electrolyte is commonly used; however, in case of flexible batteries, there are serious safety concerns because of a large extent of mechanical deformations are likely to induce internal short-circuit failures between the electrodes. To solve this problem, development of high-performance flexible solid-state electrolytes, such as gel polymer electrolytes and solid polymer electrolytes have been one of the key focuses in the flexible batteries field. 
Furthermore, it is expected that in Li/S battery the solid-state membrane can act as a physical barrier preventing the direct contact of the electrode components (Zhao et al., 2013; Zhang et al., 2014d). This barrier function will also help to control the dissolution of the sulfide anions from the cathode and to prevent the attack of the same anions at the anode side.

(2) A basic requirement for a flexible Li/S battery is that the electrochemical performance is not compromised under frequent mechanical strains for the long-term use (Zhou et al., 2014a). However, in the current flexible Li/S battery studies, there are no quantitative measurements to characterize their mechanical behavior except the simple bending tests of the electrodes. Hence, more in-depth analyses combined with mechanical studies and safety tests along with the deformation conditions control are needed to build fully functional free-standing $\mathrm{Li} / \mathrm{S}$ batteries.

Although the above-mentioned challenges are still remain, the recent progress in the development of flexible $\mathrm{Li} / \mathrm{S}$ batteries has been significant. We believe that further studies will lead to even more exciting results and will eventually result in practical flexible $\mathrm{Li} / \mathrm{S}$ cells for the flexible electronic devices applications such as rollup displays, touch screens, conformable active radio-frequency identification tags, wearable sensors, and implantable medical devices.

\section{ACKNOWLEDGMENTS}

This research was supported by the Subproject supported under the Technology Commercialization Project by the World Bank and the Government of Kazakhstan. The authors acknowledge the support of the Institute of Batteries LLC (Dr. I. Kurmanbayeva) for providing administrative support for this work. Yan Zhao and Yongguang Zhang are grateful of financial support by the National Natural Science Foundation of China (Grant No. 21406052) and financial support by Program for the Outstanding Young Talents of Hebei Province (Grant No. BJ2014010).

\section{REFERENCES}

Bi, H., Chen, J., Zhao, W., Sun, S., Tang, Y., Lin, T., et al. (2013). Highly conductive, free-standing and flexible graphene papers for energy conversion and storage devices. RSC Adv. 3, 8454-8460. doi:10.1039/c3ra23500a

Bresser, D., Passerini, S., and Scrosati, B. (2013). Recent progress and remaining challenges in sulfur-based lithium secondary batteries-a review. Chem. Commun. 49, 10545-10562. doi:10.1039/c3cc46131a

Evers, S., and Nazar, L. F. (2013). New approaches for high energy density lithiumsulfur battery cathodes. Acc. Chem. Res. 46, 1135-1143. doi:10.1021/ar3001348

Guo, J., Xu, Y., and Wang, C. (2011). Sulfur-impregnated disordered carbon nanotubes cathode for lithium sulfur batteries. Nano Lett. 11, 4288-4294. doi: $10.1021 / \mathrm{nl} 202297 \mathrm{p}$

Gwon, H., Hong, J., Kim, H., Seo, D. H., Jeon, S., and Kang, K. (2014). Recent progress on flexible lithium rechargeable batteries. Energy Environ. Sci. 7, 538-551. doi:10.1039/c3ee42927j

Hagen, M., Dörfler, S., Althues, H., Tübke, J., Hoffmann, M. J., Kaskel, S., et al. (2012). Lithium-sulphur batteries-binder free carbon nanotubes electrode examined with various electrolytes. J. Power Sources 213, 239-248. doi:10.1016/j.jpowsour. 2012.04.004

Hagen, M., Dörfler, S., Fanz, P., Berger, T., Speck, R., Tübke, J., et al. (2013). Development and costs calculation of lithium-sulfur cells with high sulfur load and binder free electrodes. J. Power Sources 224, 260-268. doi:10.1016/j.jpowsour. 2012.10.004
Hu, Y., and Sun, X. (2014). Flexible rechargeable lithium ion batteries: advances and challenges in materials and process technologies. J. Mater. Chem. A 2, 10712-10738. doi:10.1039/c4ta00716f

Huang, J. Q., Peng, H. J., Liu, X. Y., Nie, J. Q., Cheng, X. B., Zhang, Q., et al. (2014). Flexible all-carbon interlinked nanoarchitectures as cathode scaffolds for high-rate lithium-sulfur batteries. J. Mater. Chem. A 2, 10869-10875. doi:10.1039/c4ta00245h

Huang, X., Sun, B., Li, K., Chen, S., and Wang, G. (2013). Mesoporous graphene paper immobilised sulfur as a flexible electrode for lithium-sulfur batteries. J. Mater. Chem. A 1, 13484-13489. doi:10.1039/c3ta12826a

Jin, J., Wen, Z., Ma, G., Lu, Y., Cui, Y., Wu, M., et al. (2013a). Flexible self-supporting graphene-sulfur paper for lithium sulfur batteries. RSC Adv. 3, 2558-2560. doi:10.1039/c2ra22808d

Jin, K., Zhou, X., Zhang, L., Xin, X., Wang, G., and Liu, Z. (2013b). Sulfur/carbon nanotube composite film as a flexible cathode for lithium-sulfur batteries. $J$. Phys. Chem. C 117, 21112-21119. doi:10.1021/jp406757w

Lee, S. Y., Choi, K. H., Choi, W. S., Kwon, Y. H., Jung, H. R., Shin, H. C., et al. (2013). Progress in flexible energy storage and conversion systems, with a focus on cable-type lithium-ion batteries. Energy Environ. Sci. 6, 2414-2423. doi:10.1039/c3ee24260a

Song, J., Yu, Z., Xu, T., Chen, S., Sohn, H., Regula, M., et al. (2014). Flexible freestanding sandwich-structured sulfur cathode with superior performance for lithiumsulfur batteries. J. Mater. Chem. A 2, 8623-8627. doi:10.1039/c4ta00742e

Song, M. K., Cairns, E. J., and Zhang, Y. (2013a). Lithium/sulfur batteries with high specific energy: old challenges and new opportunities. Nanoscale 5, 2186-2204. doi:10.1039/c2nr33044j

Song, M. K., Zhang, Y., and Cairns, E. J. (2013b). A long-life, high-rate lithium/sulfur cell: a multifaceted approach to enhancing cell performance. Nano Lett. 13, 5891-5899. doi:10.1021/nl402793z

Su, Y. S., Fu, Y., and Manthiram, A. (2012). Self-weaving sulfur-carbon composite cathodes for high rate lithium-sulfur batteries. Phys. Chem. Chem. Phys. 14, 14495-14499. doi:10.1039/c2cp42796f

Wang, D. W., Zeng, Q., Zhou, G., Yin, L., Li, F., Cheng, H. M., et al. (2013). Carbonsulfur composites for Li-S batteries: status and prospects. J. Mater. Chem. A. 1, 9382-9394. doi:10.1039/c3ta11045a

Wang, D. W., Zhou, G., Li, F., Wu, K. H., Lu, G. Q., Cheng, H. M., et al. (2012a). A microporous-mesoporous carbon with graphitic structure for a high-rate stable sulfur cathode in carbonate solvent-based Li-S batteries. Phys. Chem. Chem. Phys. 14, 8703-8710. doi:10.1039/c2cp40808b

Wang, L., He, X., Li, J., Chen, M., Gao, J., and Jiang, C. (2012b). Charge/discharge characteristics of sulfurized polyacrylonitrile composite with different sulfur content in carbonate based electrolyte for lithium batteries. Electrochim. Acta 72, 114-119. doi:10.1016/j.electacta.2012.04.005

Wang, L., He, X., Li, J., Gao, J., Guo, J., Jiang, C., et al. (2012c). Analysis of the synthesis process of sulphur-poly(acrylonitrile)-based cathode materials for lithium batteries. J. Mater. Chem. 22, 22077-22081. doi:10.1039/c2jm30632h

Wang, J. L., Yang, J., Xie, J. Y., and Xu, N. X. (2002). A novel conductive polymer-sulfur composite cathode material for rechargeable lithium batteries. Adv. Mater 14, 963-965. doi:10.1002/1521-4095(20020705)14:13/14\$<\$963: AID-ADMA963\$>\$3.0.CO;2-P

Xi, K., Kidambi, P. R., Chen, R., Gao, C., Peng, X., Ducati, C., et al. (2014). Binder free three-dimensional sulphur/few-layer graphene foam cathode with enhanced high-rate capability for rechargeable lithium sulphur batteries. Nanoscale 6, 5746-5753. doi:10.1039/c4nr00326h

Yang, Y., Zheng, G., and Cui, Y. (2013). Nanostructured sulfur cathodes. Chem. Soc. Rev. 42, 3018-3032. doi:10.1039/c2cs35256g

Yin, L., Wang, J., Yang, J., and Nuli, Y. (2011). A novel pyrolyzed polyacrylonitrile-sulfur@MWCNT composite cathode material for high-rate rechargeable lithium/sulfur batteries. J. Mater. Chem. 21, 6807-6810. doi:10. 1039/cljm00047k

Yu, J., Du, N., Wang, J., Zhang, H., and Yang, D. (2013). SiGe porous nanorod arrays as high-performance anode materials for lithium-ion batteries. J. Alloys Compd. 577, 564-568. doi:10.1016/j.jallcom.2013.07.034

Zhang, Y., Bakenov, Z., Zhao, Y., Konarov, A., Doan, T. N. L., Malik, M., et al. (2012). One-step synthesis of branched sulfur/polypyrrole nanocomposite cathode for lithium rechargeable batteries. J. Power Sources 208, 1-8. doi:10.1016/j.jpowsour. 2012.02.006

Zhang, Y., Bakenov, Z., Zhao, Y., Konarov, A., Doan, T. N. L., Sun, K. E. K., et al. (2013a). Effect of nanosized $\mathrm{Mg}_{0.6} \mathrm{Ni}_{0.4} \mathrm{O}$ prepared by self-propagating high 
temperature synthesis on sulfur cathode performance in Li/S batteries. Powder Technol. 235, 248-255. doi:10.1016/j.powtec.2012.10.023

Zhang, Y., Zhao, Y., Bakenov, Z., Babaa, M. R., Konarov, A., Ding, C., et al. (2013b). Effect of graphene on sulfur/polyacrylonitrile nanocomposite cathode in high performance Li/S batteries. J. Electrochem. Soc. 160, A1194-A1198. doi:10.1149/2.068308jes

Zhang, Y., Zhao, Y., Konarov, A., Gosselink, D., Li, Z., and Chen, P. (2013c). One pot approach to synthesize PPy@S core-shell nanocomposite cathode for Li/S batteries. J. Nanopart. Res. 15, 2007. doi:10.1007/s11051-013-2007-5

Zhang, Y., Zhao, Y., Konarov, A., Gosselink, D., Soboleski, H. G., and Chen, P. (2013d). A novel sulfur/polypyrrole/multi-walled carbon nanotube nanocomposite cathode with core-shell tubular structure for lithium rechargeable batteries. Solid State Ion. 238, 30-35. doi:10.1016/j.ssi.2013.03.006

Zhang, Y., Zhao, Y., Konarov, A., Gosselink, D., Soboleski, H. G., and Chen, P. (2013e). A novel nano-sulfur/polypyrrole/graphene nanocomposite cathode with a duallayer structure for lithium rechargeable batteries. J. Power Sources 241, 517-521. doi:10.1016/j.jpowsour.2013.05.005

Zhang, Y., Zhao, Y., Yermukhambetova, A., Bakenov, Z., and Chen, P. (2013f). Ternary sulfur/polyacrylonitrile/ $\mathrm{Mg}_{0.6} \mathrm{Ni}_{0.4} \mathrm{O}$ composite cathodes for high performance lithium/sulfur batteries. J. Mater. Chem. A 1, 295-301. doi:10.1039/C2TA00105E

Zhang, Y., Bakenov, Z., Zhao, Y., Konarov, A., Wang, Q., and Chen, P. (2014a). Threedimensional carbon fiber as current collector for lithium/sulfur batteries. Ionics 20, 803-808. doi:10.1007/s11581-013-1042-7

Zhang, Y., Zhao, Y., and Bakenov, Z. (2014b). A novel lithium/sulfur battery based on sulfur/graphene nanosheet composite cathode and gel polymer electrolyte. Nanoscale Res. Lett. 9, 137. doi:10.1186/1556-276X-9-137

Zhang, Y., Zhao, Y., and Bakenov, Z. (2014c). A simple approach to synthesize nanosized sulfur/graphene oxide materials for high-performance lithium/sulfur batteries. Ionics 20, 1047-1050. doi:10.1007/s11581-014-1165-5

Zhang, Y., Zhao, Y., Bakenov, Z., Gosselink, D., and Chen, P. (2014d). Poly(vinylideneluoride-co-hexafluoropropylene)/poly(methylmethacrylate)/ nanoclay composite gel polymer electrolyte for lithium/sulfur batteries. J. Solid State Electrochem. 18, 1111-1116. doi:10.1007/s10008-013-2366-y
Zhang, Y., Zhao, Y., Sun, K. E. K., and Chen, P. (2011). Development in lithium/sulfur secondary batteries. Open Mater. Sci. J. 5, 215-221. doi:10.2174/ $1874088 X 01105010215$

Zhao, Y., Zhang, Y., Bakenov, Z., and Chen, P. (2013). Electrochemical performance of lithium gel polymer battery with nanostructured sulfur/carbon composite cathode. Solid State Ion. 234, 40-45. doi:10.1016/j.ssi.2013.01.002

Zhao, Y., Zhang, Y., Gosselink, D., Doan, T. N. L., Sadhu, M., Cheang, H. J., et al. (2012). Polymer electrolytes for lithium/sulfur batteries. Membranes 2, 553-564. doi:10.3390/membranes2030553

Zhou, G., Li, F., and Cheng, H. M. (2014a). Progress in flexible lithium batteries and future prospects. Energy Environ. Sci. 7, 1307-1338. doi:10.1039/c3ee43182g

Zhou, L., Lin, X., Huang, T., and Yu, A. (2014b). Binder-free phenyl sulfonated graphene/sulfur electrodes with excellent cyclability for lithium sulfur batteries. J. Mater. Chem. A 2, 5117-5123. doi:10.1039/c3ta15175a

Conflict of Interest Statement: The authors declare that the research was conducted in the absence of any commercial or financial relationships that could be construed as a potential conflict of interest.

Received: 08 October 2014; accepted: 15 January 2015; published online: 02 February 2015.

Citation: Zhao Y, Zhang Y, Bakenova $Z$ and Bakenov Z (2015) Carbon/sulfur composite cathodes for flexible lithium/sulfur batteries: status and prospects. Front. Energy Res. 3:2. doi: 10.3389/fenrg.2015.00002

This article was submitted to Energy Storage, a section of the journal Frontiers in Energy Research.

Copyright $\odot 2015$ Zhao, Zhang, Bakenova and Bakenov. This is an open-access article distributed under the terms of the Creative Commons Attribution License (CC BY). The use, distribution or reproduction in other forums is permitted, provided the original author(s) orlicensor are credited and that the original publication in this journal is cited, in accordance with accepted academic practice. No use, distribution or reproduction is permitted which does not comply with these terms. 